\title{
ENDOCARDIAL CUSHION DEFECTS
}

\section{COMMON ATRIO-VENTRICULAR CANAL AND OSTIUM PRIMUM}

BY

\author{
MAURICE CAMPBELL AND G. A. K. MISSEN
}

From the Cardiac Department and the Department of Pathology, Guy's Hospital, and the Institute of Cardiology

Received November 20, 1956

Advances in the surgical treatment of atrial septal defect have made the recognition of the less common varieties of practical importance. There is general agreement on the definition of ostium secundum defects but some confusion about the nomenclature of persistent ostium primum and the common atrio-ventricular (A-V) canal.

When the dorsal and ventral A-V endocardial cushions fail to fuse and to develop normally in fœtal life, the extent of this failure is reflected in the severity of the resulting defect. At one extreme lies the persistent common A-V canal furnished with anterior and posterior valve cusps each common to the two ventricles, the single orifice being continuous above with a persistent ostium primum and below with a high ventricular septal defect. The opposite extreme is simply a persistent ostium primum with, as a rule, a bifid anterior cusp of the mitral valve. Between these two extremes all gradations can occur.

Embryology. During the sixth week of fœtal life the dorsal and ventral endocardial cushions come together by their own growth and fuse to form a common mass, so dividing the A-V canal into separate right and left canals (Patten, 1949). The concave lower edge of the septum primum then joins with the fused endocardial cushions, but union does not become complete before the formation of the ostium secundum. There is some discussion as to whether this fusion is achieved solely by downward growth of the septum primum, or in part also by upward growth of the cushion tissue. The endocardial cushions give rise to the cusps of the mitral and tricuspid valves: they also combine with the inferior ends of the two conus ridges and with further cushion tissue on the crest of the muscular ventricular septum to form the pars membranacea septi, so finally separating the ventricles (Kramer, 1942).

If fusion of the dorsal and ventral cushions fails entirely, the common A-V canal persists, and with it-as integral parts of the extreme defect that we call Grade III-the ostium primum and a high ventricular septal defect, the three deficiencies being continuous. This, with other associated anomalies, is illustrated by our Case 1 (Fig.1), and an intermediate (Grade II) malformation by our Case 2 (Fig. 2). Here the dorsal and ventral cushions have just succeeded in fusing, as shown by the narrow bridge of fibrous valvular tissue attached to the upper surface of the ventricular septum, but their fusion has been insufficient to allow the formation of either the anterior leaflet of the mitral valve or the septal leaflet of the tricuspid valve, so that both valves appear to have been incompetent: no interventricular communication remains, but there is a large persistent ostium primum.

The least severe type of lesion (Grade I) usually consists of a persistent ostium primum and a bifid anterior mitral cusp. Division of the A-V canal occurs, and the tricuspid valve is commonly normal, though occasionally it may be malformed instead of - or even as well as - the mitral valve. As Wakai and Edwards (1956) have suggested, the usual version of this anomaly is evidently the 


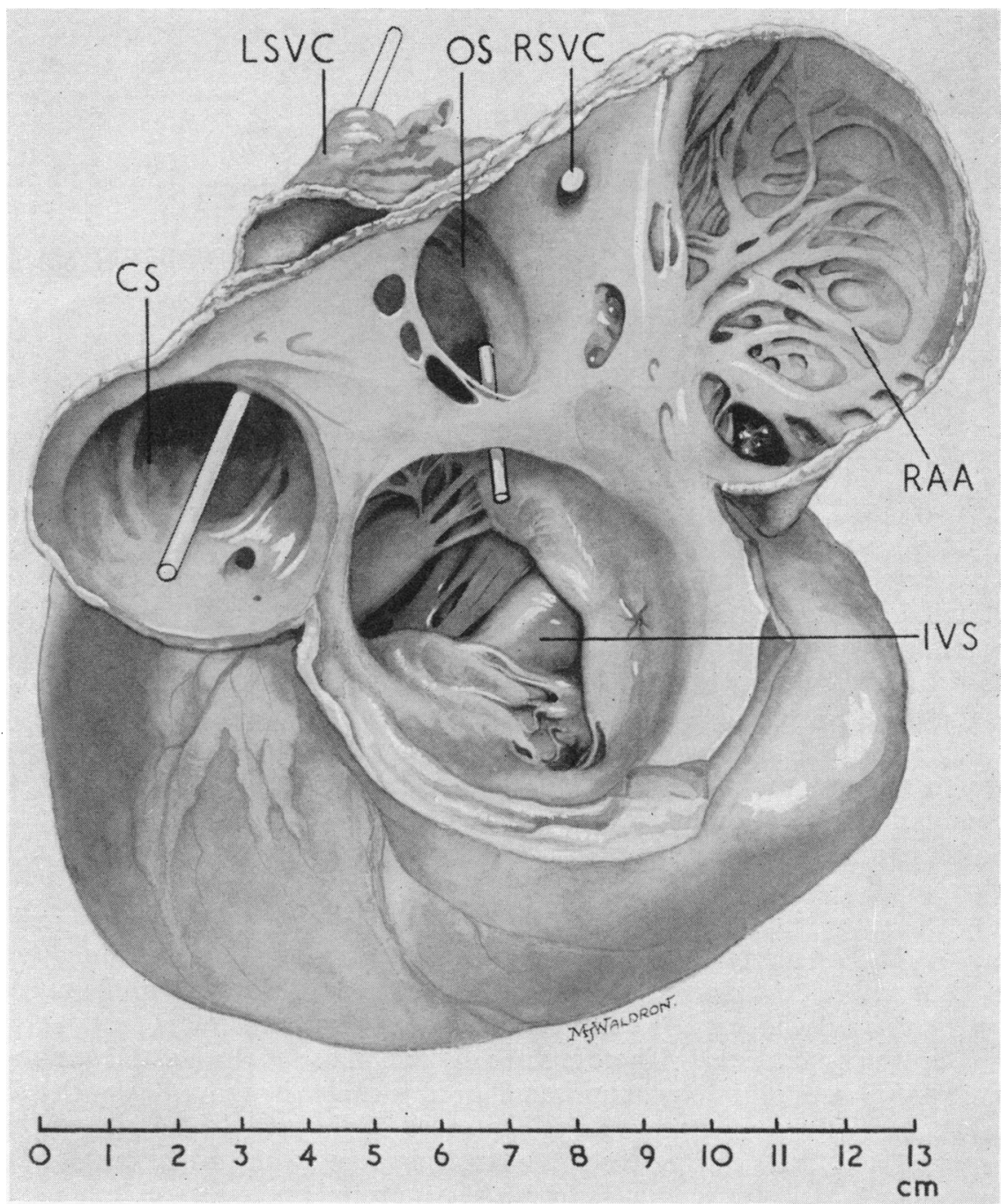

FIG. 1.-Drawing from Case 1. The hypertrophied and dilated R. atrial appendage has been reflected forwards to afford a view into all chambers of the heart from above, behind, and to the right. IVS, upper border of muscular ventricular septum. RSVC, orifice of (small) R. superior vena cava. OS, ostium secundum defect in atrial septum. CS, orifice of enlarged coronary sinus, through which the left SVC drained in the $\mathbf{R}$. atrium.

result of deficient fusion of the dorsal and ventral endocardial cushions on their left sides only. Asymmetrical fusion of these cushions clearly took place in our Case 2, in which fusion failed completely on the right, but was partially achieved on the left. Ostium primum defects associated with normal A-V valves are occasionally reported, e.g. by Blount et al. (1953, Case 3) but are generally regarded as exceptional (Abbott, 1936; Brown, 1950; Edwards et al., 1954; and Wakai and Edwards, 1956).

Nomenclature. Wakai and Edwards have designated this whole group of defects as examples of persistent common A-V canal, modifying the term by the following prefixes: (1) "complete form," which is self-explanatory; (2) " partial form," by which they mean a persistent ostium primum with a bifid anterior mitral valve-cusp; and (3) "transitional varieties" which includes 


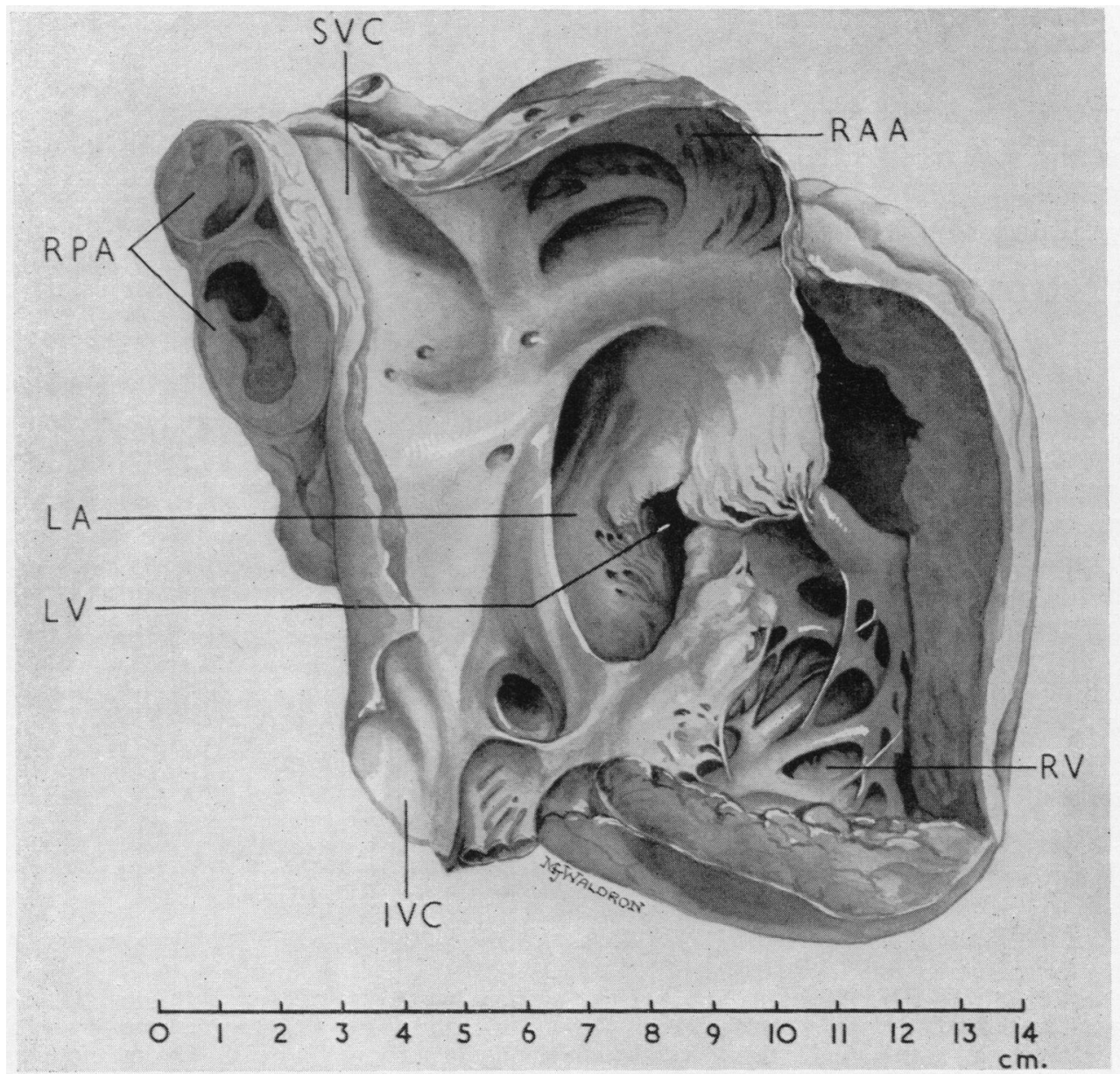

FIG. 2.-Case 2. The hypertrophied R. heart has been laid open to show the failure of fusion of the precursors of the septal cusp of the tricuspid valve, and the ostium primum defect, through which one looks into $L$. atrium and ventricle. Both primary subdivisions of the $R$. pulmonary artery (RPA) are almost occluded by thrombus.

hearts showing clefts in both the mitral anterior and the tricuspid septal valve-cusps, and a narrow bridge of valvular tissue immediately above the ventricular septum joining the anterior halves of the bifid cusps with their respective posterior halves: but for this narrow bridge a common A-V valve would be present.

We agree that a collective name for the whole group is needed that will emphasize the embryological relationships, but we cannot accept the nomenclature of Wakai and Edwards, for it is incorrect to describe an ostium primum defect as a common A-V canal, which it is not. Further evidence of the need for an accurate nomenclature, and especially for one employing a less confusing collective term, is supplied by two recent papers from the Mayo Clinic (Wakai et al., 1956; and Cooley and Kirklin, 1956). Both are concerned with series of cases of " persistent common A-V canal ": except in two cases, however, the definitive prefixes of Wakai and Edwards are omitted, to the bewilderment of the reader, who cannot be certain whether an individual patient discussed had, in fact, a single common A-V canal or a less severe malformation.

A solution lies in the term "endocardial cushion defect" recently used by Watkins and Gross 
(1955) as a synonym for the ostium primum defect. The system of nomenclature that we prefer is shown below, together with the terms of Wakai and Edwards.

Proposed classification and names

Endocardial cushion defect, Grade I $\}$ Persistent ostium primum

Endocardial cushion defect, Grade II $\{$ Endocardial cushion defect, Grade III $\}$ Persistent common A-V canal
Names proposed by Wakai and Edwards (1956)

Persistent common A-V canal, partial form

$, \quad, \quad, \quad, \quad$ transitional varieties
$, \quad, \quad, \quad, \quad$ complete form

We have no wish to displace such well-established terms as persistent ostium primum and persistent common A-V canal, provided that the latter is used only when truly applicable, but there is no accepted name for the Grade II defects which therefore lead to confusion. Persistent common A-V canal is clearer and more easily understood than the alternative terms of ostium atrioventriculare commune or atrio-ventricularis communis.

We think the term endocardial cushion defects has the following advantages. First, it emphasizes the kinship of a range of embryologically related malformations by directing attention to a developmental failure that, in varying degrees, is common to all the grades of defect within the group. Secondly, it is accurate as a collective term for the whole group, neither overstating nor understating the severity of the anomaly in any individual case: with the addition of an appropriate suffix it can be used with equal propriety to indicate all the principal degrees of maldevelopment. Finally, it provides a satisfactory name for the intermediate forms exemplified by our Case 2 and in three cases of Wakai and Edwards.

Case 1. Endocardial cushion defect, Grade III (persistent common atrio-ventricular canul). Second (ostium secundum) atrial septal defect. Stenosis of bicuspid pulmonary valve. Rudimentary accessory tricuspid orifice. Persistent L. superior vena cava.

The mother of this girl said that her lips were first cyanosed at the age of five months, and breathlessness was noticed at eighteen months when she began to walk. At the age of six when first seen by us, she had central cyanosis and was somewhat disabled though she could walk half a mile. She did not squat. A systolic murmur and thrill were found widely over the left side, and below the pulmonary area a diastolic murmur was heard at some visits but not regularly. The heart was large (c.t.r. $60 \%$, Fig. 3A) and this was thought to be due mainly to the right atrium and right ventricle but partly to the left ventricle as well. The lung fields looked dense but there was no pulsation beyond the hila and the pulmonary flow did not seem much increased. The electrocardiogram showed a large broad $P$ wave in several leads suggesting strain on both atria, but no ventricular preponderance; the primary $r$ wave was so minute that one could hardly speak of a secondary $R$ wave (Fig. 4A).

When she was 12 she was no more disabled and her heart was no larger but she was more cyanosed and now had right ventricular preponderance (Fig. 4B). She was admitted for catheterization, which proved a left-to-right shunt into the right atrium (S.V.C. $43 \%$, R.A. $71 \%$ ) presumably through an atrial septal defect, and revealed a left-sided S.V.C. that drained into the right atrium through the coronary sinus. The pressure in the atria was almost the same (R.A., 11/6; L.A., 10/6). The oxygen saturation on the left side was not much higher than on the right (F.A. 79\%; L.A. 75\%; R.A. 71\%) so that it seemed as if there was also a right-to-left shunt at atrial level, though the pressure in the right ventricle (51/6) was much lower than in the left (118/11). The systemic flow was $2 \cdot 4$ litres and the pulmonary flow $4 \cdot 1$ litres a minute with an overall left-to-right shunt of 1.7 litres, which explained why the pulmonary flow had not seemed very large on radioscopy. Two years later, when she was 14, she looked a healthy girl and could walk four miles, but we were shocked by the increased size of her heart (c.t.r. $70 \%$ (Fig. 3B)) especially to the right.

She was, therefore, admitted for reinvestigation to decide if surgical treatment was possible. While waiting she developed supra-ventricular paroxysmal tachycardia at a rate of 164 a minute: it could not be stopped and she developed congestive heart failure and died three days later. Permission was granted for examination of the heart only.

Necropsy. The pericardium was normal. Inspection of the heart in situ showed gross enlargement, especially of the right side (Fig. 5), and a persistent left S.V.C. The heart weighed $425 \mathrm{~g}$. (range for normal 

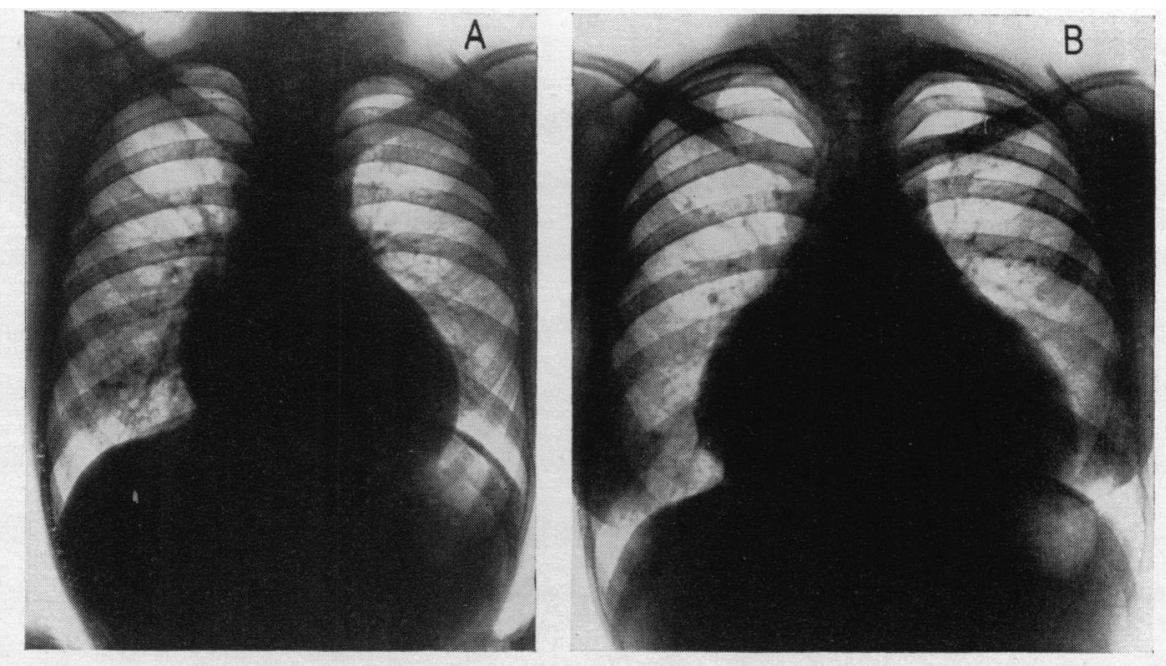

FIG. 3.-Teleradiograms of the heart, showing progressive enlargement, especially of the right side. (A) In 1948 when she was 6 and again in 1954 the cardiothoracic ratio was 60 per cent. (B) In 1956 shortly before her death it was 70 per cent. Case 1 with a Grade III endocardial cushion defect.

women of the same stature, $263 \pm 30 \mathrm{~g}$.; Zeek, 1942). Its maximum transverse diameter across the bases of the ventricles was $122 \mathrm{~mm} ., 13 \mathrm{~mm}$. more than the distance from apex to base of ventricles.

The R. atrium was hypertrophied and enormously dilated: the I.V.C. and a small R. S.V.C. entered it in normal fashion, and the L. S.V.C. via the coronary sinus, which was, therefore, greatly enlarged, its atrial orifice measuring $35 \times 30 \mathrm{~mm}$. (Fig. 1). The atria communicated by way of two large septal defects. Above was an ostium secundum defect bounded posteriorly by a fenestrated remnant of the septum primum (Fig. 1 and 7): including the fenestrae, it measured $32 \mathrm{~mm}$. vertically by $28 \mathrm{~mm}$. sagittally (the heart being considered for convenience of description as vertical with the apex pointing downwards). Separated from this defect by a narrow band of septal muscle, only $10 \times 3 \mathrm{~mm}$. in cross-section, was a large ostium primum defect with a falciform upper border. This was continuous through a common A-V canal with a high ventricular septal defect, bounded below by the upper edge of the muscular ventricular septum (Fig. 1 and 7 ), which was concave anterio-posteriorly, though convex from side to side. The entire resultant defect measured $43 \mathrm{~mm}$. sagittally $\times 35 \mathrm{~mm}$. vertically.

The common A-V canal (Fig. 1 and 6) measured $50 \mathrm{~mm}$. across its greatest diameter; its valve consisted of one large anterior and one large posterior cusp, each common to the two ventricles, with a third smaller cusp confined to the $\mathrm{L}$. ventricle.

The wide posterior cusp was attached by chordæ tendineæ to papillary muscles in both ventricles and to the right side of the septum. Its anterior edge was opaque, thickened, and rolled, while the cusp itself was widely and closely bound down to the upper edge of the muscular ventricular septum by fibrous tissue, which must have prevented it from floating into apposition during ventricular systole, and so made the valve incompetent. The wide anterior cusp (Fig. 6) extended, in addition, around the lateral aspect of the R. ventricle to meet the common posterior cusp. The former was about $2 \mathrm{~mm}$. thick and was anchored by chordæ to the anterior papillary muscles of both ventricles and also to accessory papillary muscles of the right, but unlike the posterior cusp was not attached to the ventricular septum. A group of short chordæ arising from the anterior papillary muscle of the $R$. ventricle was attached to the under surface of the common anterior cusp away from its free margin. At this point the cusp was pierced by a small puckered perforation (Fig. 1), evidently a rudimentary accessory tricuspid orifice,' the result of incomplete fusion of the ventral and R. lateral A-V endocardial cushions at this point (see Wimsatt and Lewis, 1948). The third cusp was confined to the L. ventricle and represented the posterior cusp of the mitral valve. It was of normal structure, and was attached by chordæ to the anterior and posterior papillary muscles, principally to the latter. The ventricular septum was much hypertrophied, its maximum thickness being about $25 \mathrm{~mm}$. The pars membranacea was absent.

The R. ventricular wall was greatly hypertrophied, being $12 \mathrm{~mm}$. thick in the outflow pathway $20 \mathrm{~mm}$. below the pulmonary valve (normal range 2-3 mm.; Saphir, 1951). The infundibulum was otherwise normal, but there was moderate stenosis of the pulmonary valve, which was bicuspid owing to fusion of its posterior and R. anterior cusps. Both cusps were abnormally thick and opaque with wrinkled surfaces, 
and the fusiform valvular orifice measured $11 \times 6 \mathrm{~mm}$. The internal diameter of the pulmonary trunk just above its valve was $13.5 \mathrm{~mm}$., and that of the aorta at a corresponding level, $11 \mathrm{~mm}$.

The pulmonary veins drained normally into the L. atrium, which showed moderate hypertrophy but little dilatation. The $\mathrm{L}$. ventricle was hypertrophied $(14 \mathrm{~mm}$.). The aortic valve cusps were thickened and reddened but there was no fusion: both aortic and pulmonary valves appeared competent. The coronary arteries were small, thin-walled, and patent throughout. The myocardium appeared normal.

Case 2. Endocardial cushion defect, Grade II. Aortic hypoplasia. Massive thrombosis of arteriosclerotic pulmonary trunk and arteries. Pulmonary infarction. Broncho-pulmonary mycotic infection (?Aspergillus).

This woman, aged 38 when she died, knew she had a murmur when she was 7, but had no symptoms. At 19 she became a nurse at Guy's Hospital although her heart murmur was noted. She completed her training without difficulty, but was unduly tired after a period of heavy work. In 1944, when she was a Sister and aged 27, she became dyspnœic on hills and cyanotic in cold weather: unfortunately, no X-ray or cardiographic examination was made at this time or earlier. In 1946 she married and went to India and became aware of some disability. After hysterectomy for recurrent menorrhagia, she began to notice 


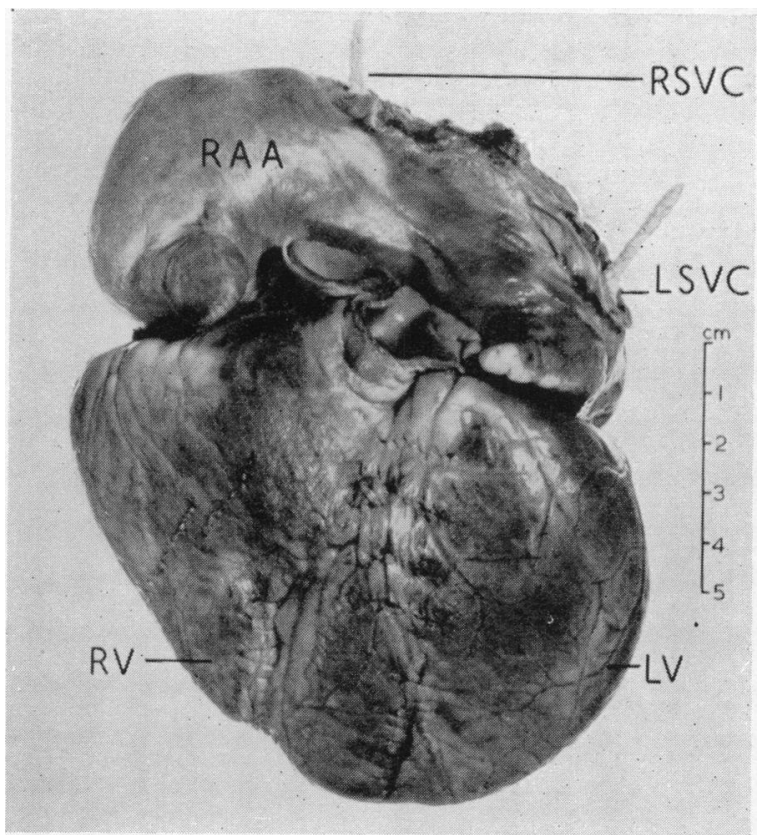

Fig. 5.-Case 1. Anterior aspect of the heart, showing great enlargement of $\mathbf{R}$. atrial appendage and $\mathbf{R}$. ventricle. The $L$. ventricle is less enlarged. The markers indicate the sites of entry of the two superior venæ cavæ.

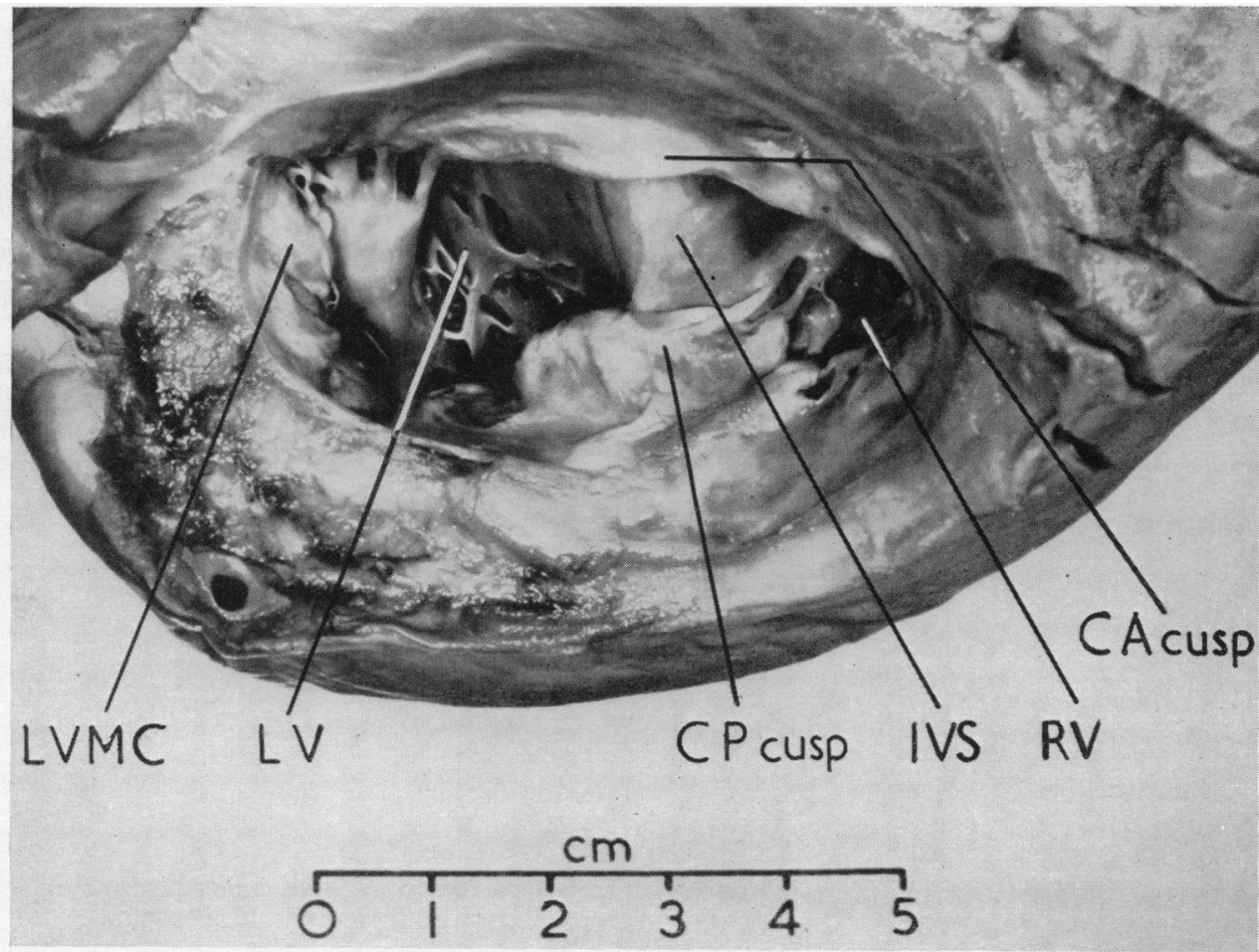

Fig. 6.-Case 1. The common atrio-ventricular canal from above after reflection of the atria forwards. CA cusp and CP cusp, common anterior and posterior cusps. IVS, ventricular septum. LVMC corresponds to posterior cusp of mitral valve. 
hills more and, in 1950, had to give up cycling. It was difficult to say when her cyanosis had become permanent, probably about 1948 .

In 1953 when she was 35 years old and was becoming severely disabled, she was examined. She had classical signs of atrial septal defect and pulmonary hypertension, a large heart (c.t.r. 64\%), a tapping apex beat, a systolic murmur and thrill well heard towards the apex, and a loud second sound in the pulmonary area. The blood pressure was 120/85. The cardiogram showed gross right ventricular preponder-

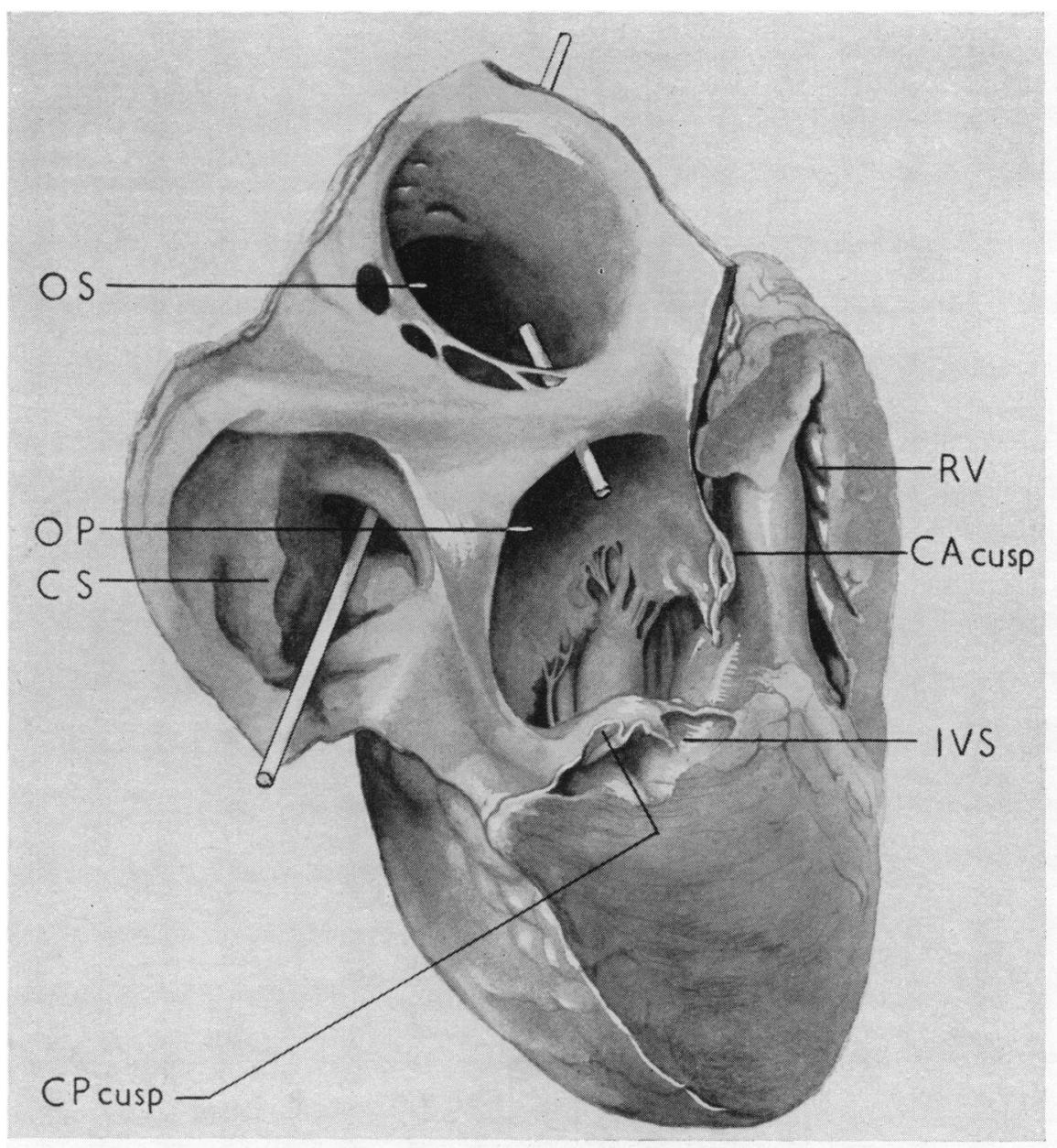

FIG. 7.-Drawing from Case 1. The greater part of the $\mathbf{R}$. atrium and ventricle have been removed to demonstrate the inter-ventricular communication beneath the cusps of the A-V valve. OS, ostium secundum defect. OP, ostium primum defect. CS, orifice of coronary sinus (rod in left SVC). CP cusp and CA cusp, divided common posterior and anterior cusps. IVS, upper edge of muscular ventricular septum. RV, hypertrophied wall of $R$. ventricular outflow pathway.

ance with S-T depression and/or T inversion in leads II, III, and V1 to V4, and a P-R interval of 0.23 sec. There was moderate central cyanosis, although radioscopy still showed increased pulsation in the pulmonary branches, which were enormous.

At catheterization a few months later the pressure was the same in both atria $(5 /-1)$. There was a right-to-left shunt (arterial $\mathrm{O}_{2}, 76 \%$ ) and a smaller left-to-right shunt; the pressure in the pulmonary artery was $140 / 62 \mathrm{~mm}$., slightly above the systemic pressure; and the pulmonary arteriolar resistance was greatly 
increased (32 units). The clinical diagnosis was bi-directional shunts through an atrial septal defect with pulmonary hypertension.

She became much worse during the next year when she was thought to have had a pulmonary embolism though, in retrospect, this was almost certainly pulmonary thrombosis. She began to get cardiac asthma and had to confine her activity to the lightest housework. She generally had two days in bed each week and needed a low salt diet with digitalis and mersalyl. In 1956, three years after her catheterization, she became worse rather suddenly with attacks of unconsciousness on the slightest exertion, and died after a few days in hospital. A necropsy was performed by Dr. C. H. R. Knowles, to whom we are indebted for his report, and for the heart and lungs.

Post-mortem Findings. The heart (410 g.) was enlarged (Fig. 8A). The two venæ cavæ and the coronary sinus entered the R. atrium normally. The foramen ovale was patent to the probe, but of normal valvular structure. Much of the atrial septum was absent as there was a large ostium primum defect measuring $49 \times 32 \mathrm{~mm}$. (Fig. 2). It was bounded below by the upper border of the muscular ventricular septum, to which malformed and thickened A-V cusps were firmly bound down (Fig. 9). The pars membranacea septi was absent. The R. atrium was moderately hypertrophied and dilated.

Both the mitral and tricuspid valves had, in effect, three cusps. The rather small posterior mitral cusp was anchored by chordæ directly to the ventricular wall; otherwise it was normal. Owing to maldevelopment and incomplete fusion of the ventral and dorsal endocardial cushions, the anterior mitral cusp was represented by two short, thick, fibrous cusp-like structures, one anterior and one posterior, which just met and became continuous on the upper surface of the ventricular septum, to which both were firmly and extensively bound down (Fig. 9). Clearly this valve had been incompetent: this had not been recognized in life though the systolic murmur and thrill had been specially noted in the mitral area. The bases of both these cusp-like structures were continuous with the anterior and posterior components respectively of the septal cusp of the tricuspid valve. These had remained completely unfused and, though thickened and malformed, were more supple than their mitral counterparts. The anterior component was anchored to the anterior papillary muscle of the $\mathbf{R}$. ventricle, and the posterior by short chordæ to the right side of the ventricular septum. The anterior and inferior cusps of the tricuspid were normal, except that the latter was fused with the posterior component of the septal cusp: if this had not been so, the tricuspid valve would have had four cusps. It too had almost certainly been incompetent from birth.

The R. ventricle was dilated and greatly hypertrophied (Fig. 2), the wall of its outflow pathway being $14 \mathrm{~mm}$. thick at a level $20 \mathrm{~mm}$. below the pulmonary valve (normal 2-3 mm.). There was no pulmonary stenosis, either valvular or infundibular: the valve-cusps were normal and the ring of normal diameter $(27 \mathrm{~mm}$.). Beginning just above the valve-ring there was massive thrombosis of the pulmonary trunk, extending along both arteries and their main subdivisions into the lungs. Transverse cuts across these vessels revealed that the process had been one of gradual accretion over a long period. Furthest from the slit-like lumina that remained the thrombus was hard, yellow, and laminated, with calcification in the oldest strata, whereas adjacent to the lumina it was dark red thrombus of recent origin (Fig. 8B). All these arteries showed a great increase in external diameter, but the lumina remaining were small by comparison.

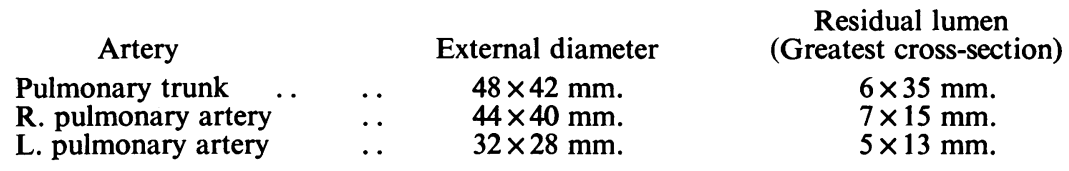

Indeed the branch to the $\mathrm{R}$. upper lobe became totally occluded by thrombus before it entered the lung, while the main artery of the R. lower lobe had only just entered before it also became occluded: in both cases occlusion had only become complete terminally.

The four pulmonary veins opened normally into a $\mathrm{L}$. atrium that was moderately hypertrophied and dilated, as was the L. ventricle. The aortic valve-cusps were normal, but the valve-ring was only $15 \mathrm{~mm}$. (normal $24 \mathrm{~mm}$.) in diameter. Immediately above their valves the walls of pulmonary trunk and aorta were of the same thickness, while the pulmonary trunk soon became dilated (Fig. 8B). The coronary arteries were normal throughout, showing none of the severe hypoplasia found in the aorta, whose descending arch was only $9 \mathrm{~mm}$. in internal diameter. No ductus arteriosus was found.

Both pleural sacs were traversed by old fibrous adhesions, especially over the medial segment of the R. middle lobe: this showed severe shrinkage and fibrosis of long standing, possibly the end-result of past infarction. At the apex of the R. upper lobe was a recent red infarct with overlying fibrinous pleurisy. The cut surfaces of the lungs revealed that the massive thrombosis extended into all the major branches of the R. pulmonary artery and also those of the L. upper lobe, while throughout both lungs there was atheromatous thickening of the walls of arteries of 3-5 $\mathrm{mm}$. in diameter. In the smallest arteries too, 
thickening of the walls could be seen with the lens. The R. bronchial artery was slightly enlarged. The parenchyma of both lungs had a brown tinge. In the apical segment of the L. upper lobe was a collapsed sub-pleural cavity about $15 \times 10 \times 7 \mathrm{~mm}$. Nearby in the lung parenchyma were several firm rounded nodules, yellow in the centre, grey at the periphery, and up to $5 \mathrm{~mm}$. in diameter.

The only other noteworthy finding was a congenital shortening or failure of fixation of the colon, as a result of which it possessed no splenic flexure.

Histological Findings in the Lungs. Sections from both upper and both lower lobes were examined. With the exception of a few localized lesions, which will be described, the changes were broadly similar throughout. In describing the various orders of branches of the pulmonary arterial tree, the nomenclature of Brenner (1935) is used.

The elastic arteries collectively showed the following changes: (a) complete or almost complete occlusion by organized or organizing thrombus, or eccentric narrowing from the same cause (Fig. 10A and B); (b) a gradation of changes ranging from a moderate degree of fibro-elastic sub-intimal thickening, with or without collections of foamy macrophages in its deeper part, through a more severe degree of the same change with narrowing of the lumen, to severe atheroma with patchy medial atrophy; $(c)$ a moderate degree of medionecrosis, seen in elastic arteries of the L. lung only, and characterized by interstitial deposition in the media of amorphous basophilic material which stained metachromatically with toluidine blue; and (d) early medial calcification, seen in a single artery only.

The muscular arteries showed the following abnormalities: first, complete occlusion or else narrowing of the lumen-sometimes eccentric - by organized or organizing thrombus (Fig. 10D); secondly, subintimal fibrosis, sometimes severe (Fig. 10C); and finally medial hypertrophy shown by thickening and 


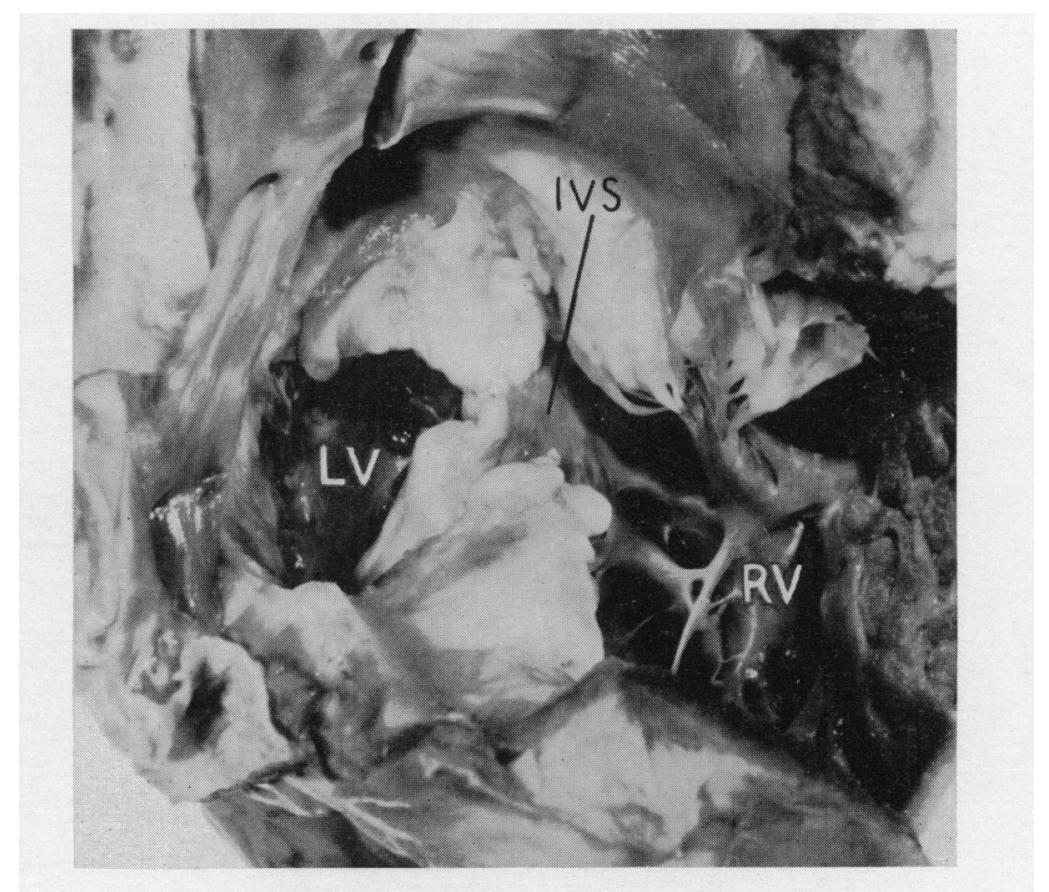

FIG. 9.- Case 2. The atrio-ventricular valves from above, behind, and to the right, after incision of the $\mathbf{R}$. ventricle with division of the anterior tricuspid leaflet. The deformed precursors of the anterior mitral cusp are seen to have fused only at the mid-point of the ventricular septum (IVS). The precursors of the septal tricuspid leaflet have failed to fuse.

reduplication of the internal elastic lamina (Fig. 10C). In one instance as many as six laminæ could be counted.

The condition of those vessels between capillary size and $100 \mu$ in diameter, that is, the group including both arterioles and venules-which may be impossible to distinguish-was variable: some showed little change, whereas others were severely altered. Sub-intimal fibrosis leading to great reduction in lumen was common (Fig. 10F), as was thickening of the elastica with or without reduplication (Fig. 10E), while a few vessels showed complete fibrous occlusion. The appearance of a distinct media bounded by two elastic laminæ, as reported by Heath and Whitaker (1955), was rarely seen. While it is clearly begging the question to postulate that the vessels showing these changes are arterioles, this seems a reasonable working hypothesis.

The lung parenchyma showed moderate patchy emphysema throughout, and several circumscribed foci of old sub-pleural fibrosis with overlying fibrous adhesions, possibly the remains of past infarcts. Recent infarction at the R. apex was confirmed, and found to be complicated by early suppuration.

The abnormal zone of lung at the L. apex was one of old collapse with fibrosis and bronchiolectasis. Several dilated bronchioles contained radiate masses of branching, septate, fungal mycelium surrounded by pus, while at least one such mass lay within a granuloma in the lung parenchyma, made up of macrophages, plasma cells, lymphocytes, and giant cells. The mean diameter of the mycelium was 3.7 . No fruiting-heads of the fungus were seen in any section, and, as only formalin-fixed tissue was available, it was impossible to identify it by culture. The organism was very probably Aspergillus fumigatus, which grows well in pulmonary infarcts (Hinson et al., 1952; Riddell, 1952 and 1956).

Comment. This patient had at first a large left-to-right shunt, and a large pulmonary blood flow, and later consequent pulmonary hypertension, to which all the vascular changes found can be related. The great size of the pulmonary arteries mirrors the initially high flow. Pulmonary hypertension leads to compensatory medial hypertrophy of muscular arteries, and to thickening and duplication of the elastica of arterioles. Atherosclerosis of the main trunks and large elastic arteries is a familiar concomitant of longstanding pulmonary hypertension, though their precise relationship is uncertain. Slowing of the blood flow in such arteries is liable to lead to mural thrombosis, with subsequent spread both distally and proximally; and, as the thrombus forms, small fragments may be broken off it and carried distally as emboli, 

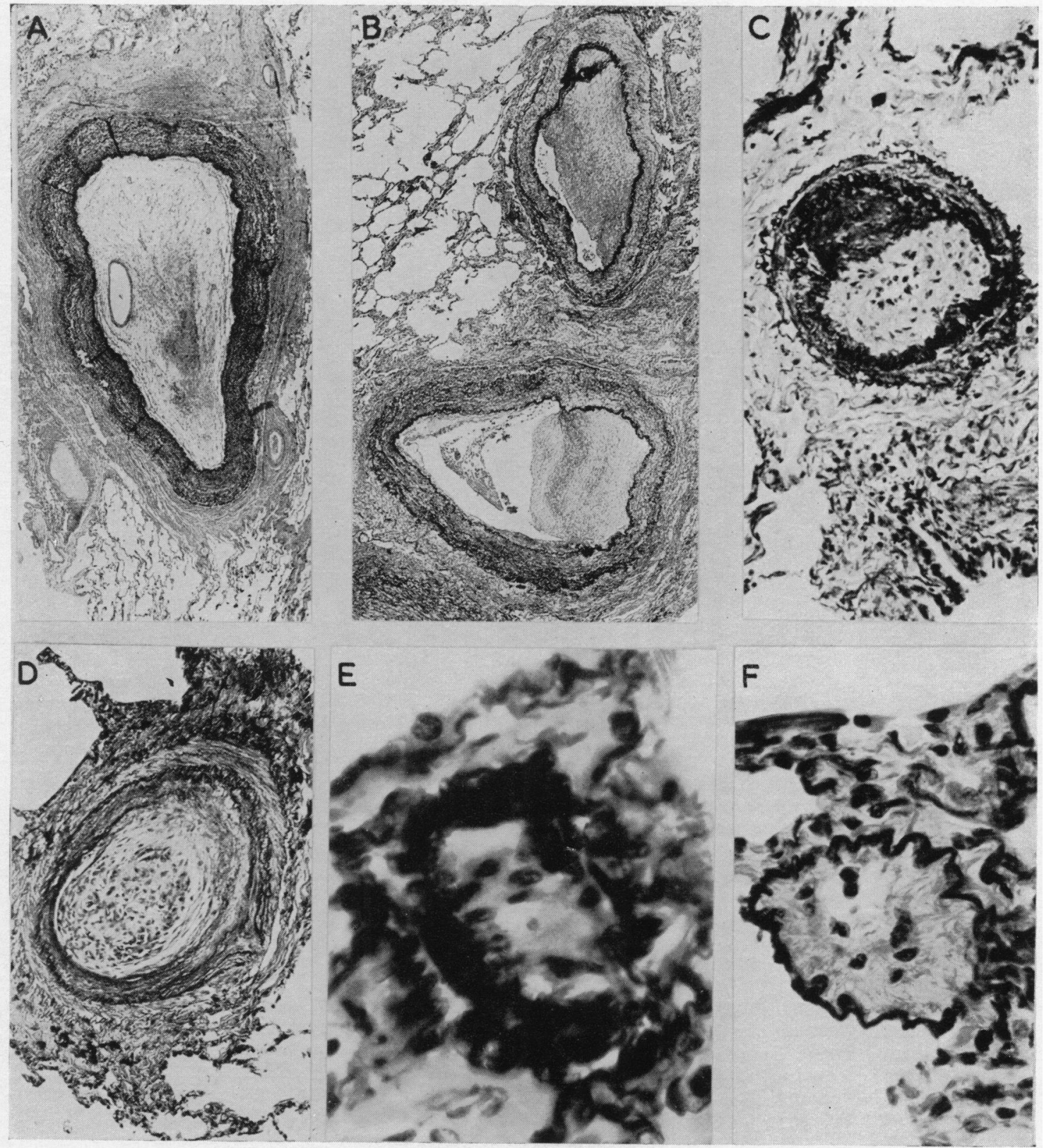

FIG. 10.-Case 2. Photomicrographs of pulmonary vessels. All sections are stained by the Weigert van Gieson method, elastic tissue appearing black. (A) An elastic artery almost completely occluded by organized thrombus. Several recanalizing channels of capillary size are seen, and one larger one. $\times 19$.

(B) Two elastic arteries $(1.5$ and $1.9 \mathrm{~mm}$.) eccentrically narrowed by organized mural thrombus. $\times 19$.

(C) A muscular artery $(170 \mu)$, showing medial hypertrophy with thickening and reduplication of the internal elastic lamina. The lumen is almost obliterated by lightly-stained collagen. $\times 182$.

(D) A muscular artery $(400 \mu)$ blocked by organized thrombus, through which pass a few recanalizing channels of capillary size. $\quad \times 96$.

(E) A (presumed) pulmonary arteriole $(50 \mu)$. The elastica shows not only hypertrophic thickening, but also reduplication. In parts of the circumference there is a suggestion of a medial coat. Except for a few fine channels, the lumen is obliterated by collagen. $\times 785$.

(F) Another (presumed) arteriole $(75 \mu)$. The elastica is thickened and there is eccentric sub-intimal fibrosis with reduction of the lumen. $\times 455$. 
impacting in vessels of various calibres and becoming organized. The degree of fibrous stenosis ultimately remaining at these sites depends upon the success or otherwise of recanalization. Harrison (1948) demonstrated a strong tendency to recanalization after experimental pulmonary embolism had been produced in rabbits by injecting human fibrin.

The work of Gibbon et al. (1932) is relevant to this patient's long survival despite much obstruction. In experiments on cats they showed that gradual occlusion of up to 60 per cent of the cross-sectional area of the pulmonary trunk was without significant effect on the systemic arterial or venous pressures; obstruction of from 60 to 85 per cent led to a rise in venous pressure and a fall in cardiac output and in blood pressure; and only when more than 85 per cent was occluded did death result. In Case 2 the mural thrombus in the main trunk and arteries grew progressively by accretion until it obstructed them so severely that death ensued, but the occlusion took place very gradually in arteries that were already much dilated: these two conditions would clearly favour prolonged survival.

It is interesting to compare these pulmonary vascular changes with those recorded in patent ductus arteriosus by Heath and Whitaker (1955), who found a close relationship between the histological changes in the vessels and the pulmonary arterial pressure. The changes found in two of their cases with a high pressure bore a close resemblance to those in our Case 2, except that they encountered no thrombosis of major arteries, while in our Case 2, whose pulmonary pressure had been 140/62 mm. three years before, a media was rarely seen in the supposed arterioles.

Severe pulmonary hypertension is now regarded as a contra-indication to operative treatment of endocardial cushion defects (Watkins and Gross, 1955; Cooley and Kirklin, 1956).

\section{Discussion}

An early report of endocardial cushion defect is that of Peacock (1846-48). His description of the heart from a girl of 10 suggests that she had a persistent ostium primum, a bifid anterior mitral cusp, and an incomplete pars membranacea septi which bulged aneurysmally to the right.

Rokitansky (1875) gave an anatomical description of seven hearts that he considered showed defects of the septum primum. One appears to be an example of the type of high atrial septal defect associated with anomalous pulmonary venous drainage (Trounce, 1953; Hudson, 1955; and Ross, 1956), now called the sinus venosus type. The remaining six all had ostium primum defects and an anterior cusp of the mitral valve that was bifid in all and completely cleft in four: the two components of this cusp were, in each case, fused with the adjacent leaflets of the tricuspid valve above the ventricular septum, but no other malformation of the tricuspid was mentioned. A high ventricular septal defect complicated two cases.

Keith (1909) records having seen 14 examples of the Grade III lesion: they are not described in detail but the essential anatomy is admirably demonstrated by two sketches, which incidentally show also a bicuspid pulmonary valve and what appears to be an ostium secundum defect, as in our Case 1. In Keith's experience the Grade III lesion was usually associated with other defects, such as complete transposition of the great trunks or pulmonary stenosis; death usually occurred in childhood and he had not seen this anomaly in the heart of an adult. Good accounts of single cases are given by Robson (1931), Robinson (1941), and Moragues (1943).

Association with Mongolism. Gunn and Dieckmann (1927) described the hearts of two mongols, aged 4 and 12 months respectively, both with a typical Grade III defect. The frequent association of Grade III and Grade I lesions with mongolism has been stressed by Abbott (1936) and others. Brown (1950) says that half of the 40 reported Grade III cases have been in mongols, and 3 of the 6 assorted cases of Rogers and Edwards (1948) were mongols. The Grade III defect is certainly more common among mongols than among other children but only a seventh of the mongols with congenital heart disease have it, the other defects being of very varied types (Evans, 1950).

The Presence of Cyanosis. Taussig (1947) discusses the clinical and hæmodynamic aspects of the Grade III lesion, and states that, as a rule, the shunt is from left-to-right and there is no cyanosis. In general, the condition is said to be acyanotic and liable to be mistaken for an atrial or ventricular septal defect, but some patients have slight or moderate cyanosis from an early age. This is said to be due generally to additional lesions, particularly pulmonary stenosis (Métianu et al., 1954), but must also be influenced by the size of the defect. In our Case 1 it seemed as if 
blood from the enormous right atrium must have passed direct into the left ventricle, and that this was probably one source of her right-to-left shunt.

Prognosis. The prognosis is bad and many patients die in the first two years. The heart is of normal size at birth and Taussig (1947) says it increases slowly; it may, however, increase quickly and become very large, this depending on the size of the defects.

Rogers and Edwards (1948), reporting 6 cases of endocardial cushion defect (4 of Grade III and 2 of Grade I), analyzed the clinical features of these and 50 reported cases that they regarded as acceptable. Their conclusions are based on a series that included both Grade III and Grade I defects. More than half died before one year while only 5 survived beyond the age of 30 , the median age at death being 10 months. Bacterial endocarditis occurred in 3 cases only.

Wakai and Edwards (1956) refer to three children who were very similar to our Case 2; both the mitral anterior and the tricuspid septal leaflets were bifid in each case, and there was the narrow bridge of valvular tissue that has been described. In two, both valves were thought to be severely incompetent. Their ages at death were 17 days, 6 weeks, and $3 \frac{1}{2}$ years. The mean survival time of 15 months is intermediate between that of 5 patients with Grade I defects (14 years, with a range of 5 months - 37 years) and 14 with Grade III defects (about 6 months, if one young infant of unknown age be excluded, all having died before the age of 16 months). However, reference is made to a patient who died elsewhere with a Grade III lesion at the age of 22 years.

Condition of the Mitral Valve. Persistent ostium primum is said by Abbott (1936) always to be associated with cleavage and insufficiency of the anterior mitral cusp. She considers that the heart with a Grade III lesion, including a large septal defect, functions as a biloculate organ, and therefore gives to it the confusing name of " incomplete double heart": 14 hearts are so classified in her analysis of 1000 cases and in 10 of these it was regarded as the primary lesion. These ten all died before the age of 5 with a mean of 1.5 years. It is hard to tell how many of the cases with "Defects (of) auricular septum below" (half with this as the main defect) should be classed as examples of endocardial cushion defects: Rogers and Edwards (1948) put the figure at 13. In their own two cases of Grade I defect the mitral valve was considered incompetent, while in at least 3 of their Grade III cases tethering of the common posterior cusp to the ventricular septum would have rendered the common A-V valve incompetent also. Such incompetence is of importance both in diagnosis and in surgical treatment. Edwards et al. (1954) include among the clinical features of the Grade III lesion the usual presence of a systolic murmur over the mid-præcordium and apex and the radiological finding of equal enlargement of the two ventricles, but these may occur with a Grade I lesion. Such diagnostic clues are valuable, for it is easy to confuse clinically Grade I or even Grade III lesions with a pure atrial septal defect.

\section{Recent Reports and their Bearing on Clinical Diagnosis}

Advances in cardiac surgery have made it plain that some atrial septal defects are more difficult to repair than others. In particular, endocardial cushion defects have proved both difficult and dangerous (Bailey et al., 1954), though recent reports from the Mayo Clinic are encouraging (Kirklin et al., 1955; Cooley and Kirklin, 1956). Hence the clinical recognition of these anomalies has taken on a new importance. Watkins and Gross report their experiences of the surgical repair of 43 cases of atrial septal defect, 4 of which proved to be endocardial cushion defects of either Grade I (e.g. their Fig. 3) or Grade II (e.g. their Fig. 2), all four with deformity of both mitral and tricuspid valves. Surgical closure of the ostium primum was achieved in some of these, only to be followed promptly by cardiac failure and death: they question the wisdom of closing an ostium primum that has been acting as an escape route for blood regurgitating through an incompetent mitral valve. Furthermore, dissection revealed that the bundle of His ran across the inferior margin of the defect, and was thus exposed to damage by surgical closure. Three speakers in the discussion following this paper said that surgical closure in Grade I defects not infrequently proved fatal, the third specifying complete heart block as a dangerous complication (Bailey, 1955; Lam, 1955; Lewis, 1955). 
With regard to the clinical differentiation from pure atrial septal defects, Watkins and Gross think that an endocardial cushion defect may be suspected in a patient who presents with a thrill over the lower sternum and a harsh systolic murmur along either sternal border, but can be diagnosed with certainty only by digital exploration of the atrium. Blount et al. (1956) describe five patients with an ostium primum defect, in whom the diagnosis was confirmed at necropsy in 3 and at operation in 2, and discuss the diagnosis. One (Case 3 ) was unusual in that the A-V valves were normal and the heart was not specially large, but the other four evidently had Grade I or Grade II endocardial cushion defects. This diagnosis should be suspected in a patient who seems to have a severe atrial septal defect with, in addition, signs suggesting mitral regurgitation. The A-V valve in each instance formed the floor of the defect, the mitral valve being abnormal in 4 of the 5 , and, the tricuspid in 2: the former was thought to be incompetent in all 4, and in 2 this was confirmed at operation. There was no evidence that the ventricular septum was defective in any of the 5 cases.

Wakai et al. (1956) report catheter studies of six children aged 5 months to 6 years and five adults aged 21 to 28 years. The presence of an endocardial cushion defect was confirmed in all at operation or necropsy but, with two exceptions, the precise type of defect is not stated. Most of them had a large pulmonary blood flow due to left-to-right shunts occurring both at atrial and (to a lesser extent) at ventricular levels. Three points were found to be of value in differential diagnosis. First, in 6 of the 9 cases (when the tip of the catheter had been manipulated into the left ventricle) the shaft was seen to lie much lower in the cardiac silhouette before traversing the septum than with a pure atrial septal defect. (Clearly, however, if there were an ostium secundum defect also, the catheter might traverse the septum at a higher level.) Secondly, evidence of a left-to-right shunt at both atrial and ventricular levels was found, again in 6 of the 9 cases. Thirdly, they found no preferential shunting of the venous blood from the right lung.

In one cyanotic girl studied recently, the catheter passed equally easily into the left ventricle or through the right ventricle into the pulmonary trunk with very little withdrawal and with very little change in the position of its shaft: so we thought that there was a common atrio-ventricular canal. This may be another useful point.

Toscano-Barbosa et al. (1956) report on the electrocardiographic findings in 16 proven cases of endocardial cushion defect, but again the extent of the individual defects is not defined. They found a basic uniformity that was modified only in the presence of pulmonary hypertension or of gross left ventricular hypertrophy due to mitral insufficiency; this may be of value in distinguishing this group from pure atrial septal defect.

\section{SUMMARY}

The group of cardiac malformations that have in common defective development of the dorsal and ventral atrio-ventricular (A-V) endocardial cushions may usefully be called endocardial cushion defects. They can be divided into three grades: Grade III (persistent common A-V canal), Grade II (intermediate forms), and Grade I (persistent ostium primum). Two illustrative cases are described -a girl of 14 with a Grade III defect and other anomalies, and a woman of 38 with a Grade II defect, who died as a result of massive thrombosis within the pulmonary arterial tree.

The hæmodynamic disorder usually predominant in these patients is that due to the atrial septal defect. However, the picture may be complicated by any or all of the following: (1) incompetence of one or both A-V valves or of a common valve, (2) an additional left-to-right shunt at ventricular level, and (3) associated congenital cardiac anomalies (e.g. pulmonary stenosis). The recognition of incompetence of an A-V valve-usually the mitral-helps in differentiating between an endocardial cushion defect and a pure (and therefore-ceteris paribus-more easily operable) atrial septal defect. Cardiac catheterization and electrocardiography often help in making this distinction. 
We think the possibility of a Grade III endocardial cushion defect should be considered more often in cyanotic patients whose diagnosis is uncertain.

We wish to thank Professor G. Payling Wright for his valuable advice. We are indebted to Miss M. J. Waldron for the drawings, to Mr. C. E. Engel and Mr. D. C. Payne for the photographs, to Mr. B. S. Milne for the sections, and to Mr. L. E. Till for the photomicrographs.

\section{REFERENCES}

Abbott, Maude E. (1936). Atlas of Congenital Cardiac Disease. New York. Bailey, C. P. (1955). J. thorac. Surg., 30, 487.

, Nichols, H. T., Bolton, H. E., Jamison, W. L., and Gomez-Almeida, M. (1954). Ann. Surg., 140, 805.

Blount, S. G., Balchum, O. J., and Gensini, G. (1956). Circulation, 13, 499.

Brenner, O. (1935). Arch. intern. Med., 56, 211, 457, 724, 976, and 1189.

Brown, J. W. (1950). Congenital Heart Disease. Staples Press, London and New York.

Cooley, J. C., and Kirklin, J. W. (1956). Proc. Mayo Clin., 31, 523.

Edwards, J. E., Dry, T. J., Parker, R. L., Burchell, H. B., Wood, E. H., and Bulbulian, A. H. (1954). An Atlas of Congenital Anomalies of the Heart and Great Vessels. Springfield.

Evans, P. R. (1950). Brit. Heart J., 12, 258.

Gibbon, J. H., Hopkinson, M., and Churchill, E. D. (1932). J. clin. Invest., 11, 543.

Gunn, F. D., and Dieckmann, J. M. (1927). Amer. J. Path., 3, 595.

Harrison, C. V. (1948). J. Path. Bact., 60, 289.

Heath, D., and Whitaker, W. (1955). J. Path. Bact., 70, 285.

Hinson, K. F. W., Moon, A. J., and Plummer, N. S. (1952). Thorax, 7, 317.

Hudson, R. (1955). Brit. Heart J., 17, 489.

Keith, A. (1909). Lancet, 2, 433.

Kirklin, J. W., Daugherty, G. W., Burchell, H. B., and Wood, E. H. (1955). Ann. Surg., 142, 858.

Kramer, T. C. (1942). Amer. J. Anat., 71, 343.

Lam, C. (1955). J. thorac. Surg., 30, 488.

Lewis, F. J. (1955). J. thorac. Surg., 30, 489.

Métianu, C., Durand, M., and de Balsac, R. H. (1954) in Traité des Cardiopathies congénitales, ed. E. Donzelot, and F. d'Allaines, Paris.

Moragues, V. (1943). Amer. Heart J., 25, 123.

Patten, B. M. (1949). Human Embryology. London.

Peacock, T. B. (1846-48). Trans. Path. Soc. Lond., 1, 61.

Riddell, R. W. in Marshall, G., and Perry, K. M. A. (1952). Diseases of the Chest. Vol. 1, 175, London.

, (1956). Brit. med. J., 2, 783.

Robinson, D. W. (1941). Arch. Path., 32, 117.

Robson, G. M. (1931). Amer. J. Path., 7, 229.

Rogers, H. M., and Edwards, J. E. (1948). Amer. Heart J., 36, 28.

Rokitansky, C. F. von (1875). Die Defecte der Scheidewände des Herzens: pathologisch-anatomisch Abhandlung. Vienna.

Ross, D. N. (1956). Guy's Hosp. Rep., 105, 376.

Saphir, O. (1951). Autopsy Diagnosis and Technic. New York.

Taussig, H. B. (1947). Congenital Malformations of the Heart. The Commonwealth Fund, New York.

Toscano-Barbosa, E., Brandenburg, R. O., and Burchell, H. B. (1956). Proc. Mayo Clin., 31, 513.

Trounce, J. R. (1953). Guy's Hosp. Rep., 102, 140.

Wakai, C. S., and Edwards, J. E. (1956). Proc. Mayo Clin., 31, 487.

W, Swan, H. J. C., and Wood, E. H. (1956). Proc. Mayo Clin., 31, 500.

Watkins, E., and Gross, R. E. (1955). J. thorac. Surg., 30, 469.

Wimsatt, W. A., and Lewis, F. T. (1948). Amer. J. Anat., 83, 67.

Zeek, Pearl M. (1942). Arch. Path., 34, 820. 